\title{
The Research and Practice on the Talent Cultivation Pattern in the Industrial Development of Internet of Things
}

\author{
Diao Zhijian \\ Nanchang Institute of Science and Technology, Nanchang, China
}

Keywords: industrial development need, Internet of Things (IOT), talent cultivation pattern, discussion

\begin{abstract}
The Internet of Things (IOT) is a product of information technology as well as a strong support for the high-tech industry in China. In this era, it is necessary to provide enough professionals of this filed as a growth driver. The professional courses of the Internet of Things in China start relatively early, and the major construction is still in the preliminary stage, therefore, the construction of a talent cultivation pattern in the IOT is the only way to the long-term development of the local IOT industry as well as the requirements inside the industry. Given such features, the author analyzed and discussed the current talent training mode, and proposed a training pattern keeping pace with the industrial development based on the running laws in the IOT industrial system. It is hoped that, the talent training mode can help accelerate and inject the impetus into the development of IOT, so as to sustain its long-term development.
\end{abstract}

\section{Introduction}

The state Council has attached much importance to increasing the support of IOT domestically to lay a solid foundation for the further development in this filed and regarded it as the diver of the high-tech industry. Meanwhile, it has proposed the concept of "sensing China”. Against such background, universities and colleges have realized that inevitability of the development of IOT. To follow the trend in the new era, they have opened professional courses related to IOT, and formulated practical talent training mode, conducted reform and innovation for the traditional teaching mode to meet the needs for talents in the industrial development in the regions and in the market operation.

\section{Analysis of the early development and structure of IOT}

Since the presentation of the "Sensing China", provinces and cities in China have noticed the importance of reform and planning in the IOT industry, charted a professional, systematic, and comprehensive blueprint in combination with economic trends and real conditions in the local region. In this process, the overall thinking of the industrial development has been clarified. The key is to strengthening the strategic succession effect, making breakthroughs in the core technology to promote sound and efficient development by means of demonstration projects.

In order to manifest the social value of IOT and inject the impetus into the local economy, it is necessary to open the IOT courses from the perspective of talent cultivation. Based on the real development of the universities and colleges and the $12^{\text {th }}$ Five-year Plan of IOT, a talent cultivation system is stipulated to meet the talent need for the regional IOT development [1]. At the same time, it is important to analyze the overall structure of IOT industrial system. Based on this, the tendency of the industry as well as the development of enterprises in the region shall be clarified to make a tailored talent cultivation planning scheme. The author, by investigation and discussion, has summarized the hierarchical structure of the IOT industry shown in figure 1 [2]. 


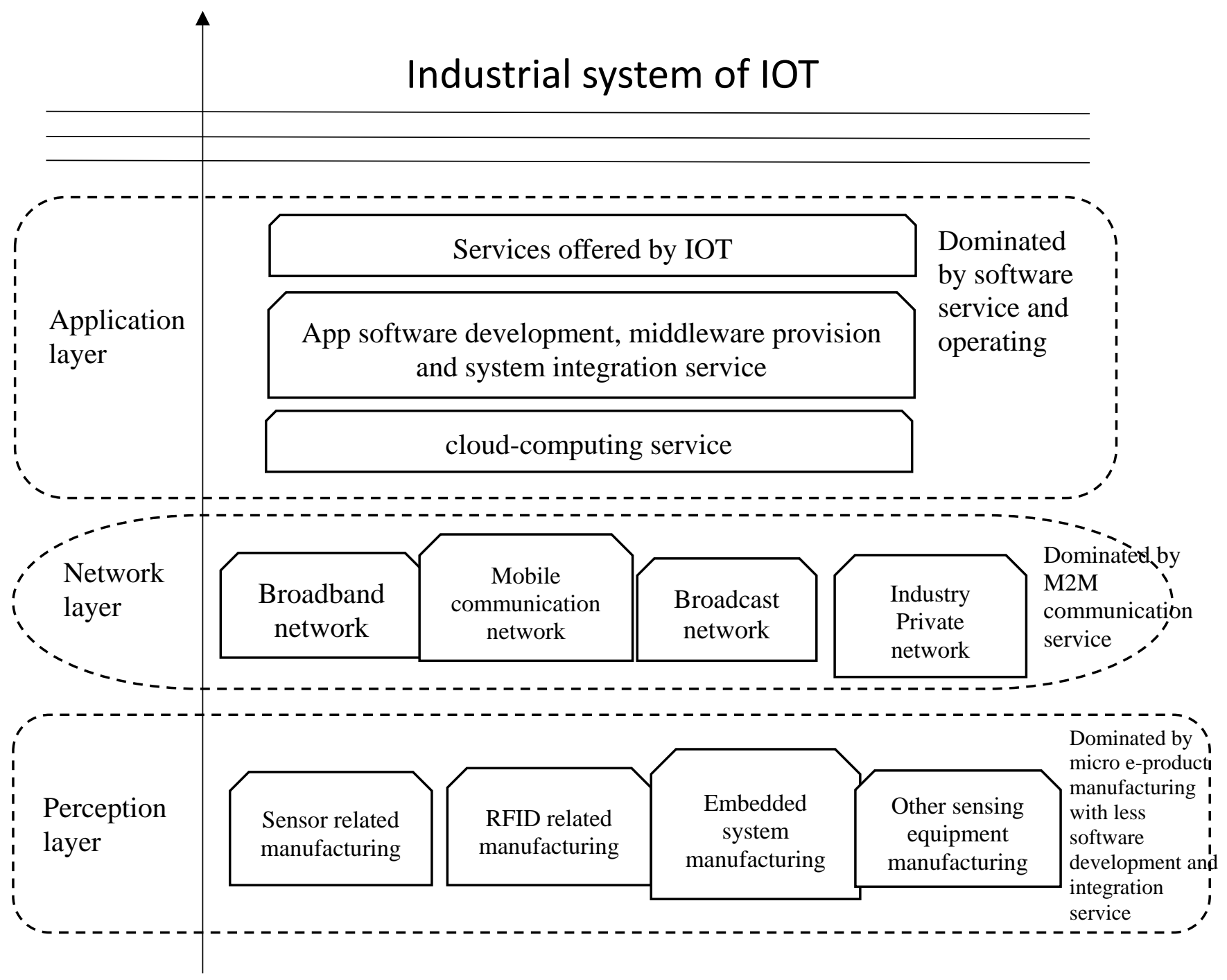

Figure 1. sketch of industrial system structure of IOT

Through the analysis of industrial system structure of IOT, it can be seen that it is composed of application layer, sensing layer and network layer.

First, application layer. It is the application of IOT that the related data information can be integrated and summarized to display its sharp sensing ability in the related system. System integration enterprises, software development enterprises belong to the application layer [3].

Second, sensing layer. Sensing layer is the foundation of the effective operation of the IOT, ranging from RFID enterprises, sensor manufacturing enterprises to embedded system manufacturing enterprises.

Third, network layer. Generally, network layer refers to the network communication enterprises, one includes exclusive communication equipment, providers, equipment production and manufacturing, the other is the telecommunication services like various network operators in telecommunication including China Mobile and China Unicom [4].

\section{The current development of IOT}

In recent years, the IOT in China has witnessed some progress, which greatly drives the social development. However, the development of IOT in many regions cannot be comparable to some major cities like Beijing, Shanghai and Jiangsu, showing the imbalance in the IOT development in China. In order to deepen the development of IOT and achieve the goal of IOT industry proposed in the" $12^{\text {th }}$ Five Year Plan", the first step is to clarify the development of IOT in the regions and 
economic growth locally so as to realize rapid development based on this [5].

Take the IOT development in an area as an example. As early as decades ago, that region began to focus on the IOT development driving the high-tech industry, and establish a high-tech management committee and dedicated technology bureau, meanwhile, it set up the industry alliance in which scientific research institutions, related enterprises, management sectors as well as universities and colleges were important sectors [6].

In addition, the local government had included IOT into the Outline of the local $12^{\text {th }}$ Five Year Plan, built IOT demonstration park and specialized exhibition center of IOT to stimulate and display the IOT industry by means of stimulation system [7].

The development of IOT involves a variety of disciplines as well as other industries. And the multiple scientific and research institutes as well as universities and colleges, private high-tech enterprises locally have made their contribution to the IOT development as a support [8].

As the IOT has laid a solid foundation in the region, the products and technologies developed by scientific and research institutions locally even cover all the industrial chains with strong momentum. According to reliable data, the number of enterprises related to IOT in the region has exceeded 400, whose real industrial scale has been over 20 billion yuan. Therefore, the IOT has seen a rapid development in the region. [9-11].

To make the development of IOT efficient and smooth, more talents are required to drive this field. It is necessary to formulate practical plans, talent cultivation strategies, and innovate the current talent training mode to cultivate more application-oriented talents in keeping with the development of IOT as well as the trend of the times.

\section{Discussion about the talent training mode in the IOT field}

When cultivating talents in universities and colleges, it is important to take the law of industrial development and the characteristics of industrial operation into consideration. Thus, the setting of majors and the subjects can meet the needs of market development. Initially, IOT Engineering will imitate the setting and schedule of computer science or electronic information engineering, based on this, courses in IOT major and related subjects are increased to fulfill the economic development locally and make innovation and reform in the research and teaching practice [12].

In the initial stage of IOT development, all problems emerge during the enrollment of the IOT, for example, lacking of teaching experience, fuzzy training positioning, unclear development after graduation, and the shortage of faculty. Therefore, the universities and colleges shall shoulder their responsibilities and play a leading role in achieving the common development and progress between enterprises and universities and colleges. Rather than a new industrial structure, many universities and colleges have clarified the future development of IOT to make the position of IOT Engineering more precise and scientific in combination of the previous teaching needs. In this process, it is important to realize the organic integration with other IOT industries based on related theories of IOT. And automation, computer science and technology, electronic information engineering and other subjects open based on the requirements for talents and the combination of industry with the major. They will serve as a supplementary means to inject impetus into the long-term development of IOT engineering [13].

\subsection{Understand the teaching goals and talent cultivation position}

In cultivating talents, universities and colleges shall take the needs for talents in the IOT development as the basic goal to ultimately, cultivate applied talents serving for local economy. Then, they should report the enrollment and opening of IOT major, summarize real student pool of internally combining the local economic growth to meet the real needs of social development as much as possible. They should show the characteristics of IOT engineering, fully understand the strategic targets of local economic development, and take key and major technologies under control to determine feasible goals.

The above goals require deep social survey and the summary of talent needs proposed by related enterprises in the field. Such data shall be integrated as the foundation of talent cultivation in order 
to improve the innovative capabilities of students, and make smart logistics, smart home, and smart agriculture as the major cultivation orientation.

\subsection{Rational subject setting to enhance the overall qualities of students}

As is known to all, the IOT industry involves so many subjects, which is an interdisciplinary major. In the talent cultivation, it is necessary to enhance the overall qualities of students from subject scheduling, setting and management, fully utilize the "Type structure to strike a balance both in depth and width, both after class and in the class, and interact with emerging science in the small class.

Besides, it is a necessary requirement to attach much importance to the scheduling of basic theory of IOT engineering, and strengthening the social responsibilities and humanistic spirits. The proposal of" mass entrepreneurship and innovation” put forward by premier Li Keqiang is definitely a social and economic requirement given the current social background. Meanwhile, it is equally important to raise innovation consciousness, lead students to communicate with their peers in the study and growth to improve their social cognitive abilities as well as their resilience.

When comes to the curriculum framework, the focus should be paid to business, management, humanity and social science, make innovation and reform of traditional teaching mode stressing only theories. In this way, the integration of social practice with the technological means will be achieved to cultivate more qualified talents.

\subsection{School-enterprise cooperation to fuel the applied talent cultivation}

Enterprises, government and universities should cooperate to realize the goal of applied talent cultivation. In order to inject vitality into the local development of IOT and offer better services, the universities and colleges should play their part in the talent cultivation, and software parks and other scientific and research institutions should communicate with enterprises of the related industrial chain, and with the local government. Take the talent cultivation of Nanchang Institute of Science and Technology as an example, it has made the practice base outside the school and school-enterprise cooperation as key goals, created a sound atmosphere in the school-enterprise cooperation, put post practice, cognition internship in the enterprise, as well as summer internship into place to help students accumulate more experience for the future, which is conducive to a sound and long-term development.

\subsection{Improve the innovation and entrepreneurial abilities by engineering competition and practice}

The previous teaching mode takes talent cultivation of a discipline as a goal and gradually, shaping a systematic knowledge system to support the education system and cultivation mode. In the process, the overall qualities of teachers are crucial. Teachers should receive related training to encourage students to take part in discipline competitions rather than training to improve their practical abilities. The startup and innovation projects of students should be put into practice, and the cultivation idea of "one project with multiple functions" should permeate into the teaching work to combine practice with theory. In the implementation of projects, students should be led to improve their cooperation abilities and practical skills so as to realize the goal of innovative leaning model and teaching method reform.

\section{Conclusion}

In a word, with the acceleration of IOT development as well as the increasingly enhancing of requirements for talents, universities and colleges shall shoulder their responsibilities to show the efficiency, rationality and scientificity of talent cultivation. The setting of curriculums, the subject structure shall meet the needs of students' growth and development, greatly improving the talent qualities. What is more, universities and colleges should make social investigations, make talent requirement proposed by related enterprises clear considering the local economic development. By enterprise-government cooperation, the efficiency of talent cultivation should be improved to inject 
impetus into the IOT development.

\section{Acknowledgement}

The paper is a subject in the teaching reform of Nanchang Institute of Science and Technology named Research on Talent cultivation mode Based on the Industrial Development of IOT (subject number: NG JG-16-49

\section{References}

[1] Zhang Yuanping. Discussion on the innovative ability and cultivation methods of the Internet of things engineering talents [J]. Electronic test, 2016, 15(14):100-100,102.

[2] Li Huawei, Peng Hongmei, Cheng Yuan et al. Research on the innovation ability and scientific research capacity of the Internet of things engineering professionals [J]. Computer education, 2014, 26(2):15-18.

[3] Li Juhu, Zhang Haiyan. Research on talent cultivation in the Internet of things in the major category of enrollment: a case study of Beijing forestry university [J]. Chinese forestry education, 2013, 35(1):22-26.

[4] Yu Lei, Li Junhuai, Wang Huaijun et al. Discussion on the cultivation mode of the practical ability of Internet of things engineering professionals [J]. Computer education, 2017, 17(8):52-56.

[5] Zheng Yuhong, Wu Pengbo, Li Li et al. Analysis on the demand of professional talents in high vocational college in Beijing, Tianjin and Hebei [J]. Modern economic information, 2015, 22(10):442-442.

[6] Luo Haohuan. Exploration of professional talents cultivation and professional construction of Internet of things engineering [J]. Communication world, 2011, 18(4):276-277.

[7] Hong Qin. A few thoughts on the cultivation of professional talents of Internet of things in universities [J]. Electronic world, 2014, 29(16):360-360.

[8] Mi Zhiqiang. Research and practice on the training of professional talents in the application of technology for the networking of higher vocational things in logistics industry [J]. Computer knowledge and technology, 2016, 12(11):121-122,124.

[9] Peng Xuanrong, Wang Min, Huang Xiaohong et al. Research and practice on the cultivation of professional computer talents in the era of Internet of things [J]. Journal of guangdong light industry vocational and technical college, 2013, 26(2):61-65.

[10] Pan Tao. Exploration on the construction of a professional curriculum system for the application of Internet of things in higher vocational colleges [J]. Value engineering, 2013, 36(31):249-251.

[11] Zhao Liuqing, Zhou Xiaoqing, Zhang Kenan et al. Research on the difference of talent cultivation in the Internet of things in Anhui university [J]. Course education research, 2016, 11(3):27-28.

[12] Cheng Xingjing, Jiang Xueqin, Liu Jiqian et al. Research on talent cultivation of Internet of things engineering based on CDIO model [J]. Education research (new teacher teaching), 2015, 10(9):269-269.

[13] Lin Xihui. Research on talent cultivation mode in higher vocational colleges based on the Internet of things [J]. New curriculum research (mid-to-double), 2014, 01(1):105-107. 